UDC: 821.134.2.09 García Lorca F. DOI: https://doi.org/10.18485/hispserb.2019.2.ch15

\author{
Mirjana Sekulić ${ }^{1}$ \\ Universidad de Kragujevac \\ Serbia
}

\title{
VIAJES Y DESCUBRIMIENTOS DE FEDERICO GARCÍA LORCA
}

\begin{abstract}
Resumen
Proponemos cuestionar el significado de viaje en la obra Impresiones y paisajes de Federico García Lorca y relacionado con este, el concepto del descubrimiento exterior e interior, proporcionados en este caso por el viaje real.

Empezamos por la idea de que el viaje era una práctica promovida desde los krausistas y aceptada por la Generación del 98 como instrumento para conocer España de cerca, una España vital por debajo de las visiones estereotipadas. De allí cuestionaremos cómo el viaje de García Lorca con otros estudiantes, organizado por su profesor Berrueta como un viaje pedagógico colectivo, partiendo de las visitas a los museos y monumentos culturales, termina en un viaje interior como su última expresión.

El objeto de este trabajo será también la interpretación imagológica de la visión de España en decadencia, que ha originado las preocupaciones de García Lorca sobre el porvenir de España.

Por último, se cuestionará el modo en el que la autoimagen de España construida por Federico García Lorca se convierte en una visión íntima, romántica y lírica. Las fronteras entre la ficción y la realidad resultan ser borrosas y el viaje por distintas ciudades españolas para el autor de Impresiones y paisajes obtiene una estructura iniciática.
\end{abstract}

Palabras clave: Federico García Lorca, Impresiones y paisajes, viajes, visiones, realidad.

\footnotetext{
${ }^{1}$ msekulic@filum.kg.ac.rs
} 


\section{Viajes pedagógicos de Berrueta}

El viaje y la vida son sinónimos, nos recuerda Luis AlbuquerqueGarcía (2011: 16), "ya que su fuente y raíz se encuentra en el desplazamiento mismo". El viaje es también un descubrimiento, no solo en sentido objetivo, sino sobre todo como la conexión entre los "aspectos exteriores y el yo secreto", en una forma de "aprendizaje y de transformación mental del yo descubridor" (Wolfzettel 2005: 11). Viajar supone enfrentarse al Otro, al ambiente distinto, a otros viajeros con los que se comparte la aventura, y a sí mismo. El viaje es la experiencia del Otro, pero también un proceso de conocimiento de sí mismo. El relato de viajes es la traducción literaria de la experiencia vital, así que, como toda traducción, añade algo nuevo, construye una visión estructurada del viaje recorrido y de sí mismo, cambiado por la experiencia (Peñate Rivero 2005: 52).

Federico García Lorca, como joven estudiante, participaba en 1915 y 1916 con otros compañeros de la universidad en las excursiones que organizaba Martín Domínguez Berrueta, el catedrático de Teoría de la Literatura y las Artes en la Universidad de Granada. Al llegar a la Universidad de Granada, Berrueta se dedicó a propiciar un acercamiento entre profesores y alumnos y proporcionar a los estudiantes un aprendizaje dinámico. En esto se nota una fuerte influencia de la Institución Libre de Enseñanza. La filosofía krausista promovía una concepción pedagógica que supone acercamiento de los alumnos a los objetos de conocimiento, por lo cual las clases experimentales y las excursiones de los estudiantes cobran una vital importancia.

Este profesor quería introducir nuevos métodos de enseñanza, y reconociendo la importancia del conocimiento de lo propio, local, nacional, organizó una serie de viajes de estudios por España. Berrueta y sus alumnos primero recorrieron Granada y sus alrededores, ampliando sus viajes por Andalucía (Baeza, Úbeda, Córdoba, Ronda) y Castilla (Madrid, Ávila, Zamora) llegando hasta Santiago, León, Burgos, La Coruña.

Los viajes pedagógicos de Berrueta se concentraron en los monumentos y visitas a los museos, revisión de obras de arte etc. En la concepción de Berrueta el viaje fue una forma de conocimiento y de enseñanza de arte, es decir, él intentaba aunar la teoría y la práctica mediante las visitas a los lugares emblemáticos de cultura española y las reflexiones directas sobre lo visto. Como explica Luis García Montero (2016) en una conferencia sobre Antonio Machado y García Lorca, en el fondo de la enseñanza de Berrueta había una concepción de la 
juventud como energía renovadora, que debe responsabilizarse de la transformación del país. Para Berrueta, el maestro no solo debía informar, sino formar en la conciencia crítica a sus alumnos. En principio, Berrueta pedía a los alumnos que tomaran notas sobre lo que veían, pero su idea no era enumerar lugares y monumentos, sino enseñar a los alumnos a reflexionar y a expresarse, como parte de su propuesta de renovación universitaria. En Lorca esa expresión será muy personal, íntima percepción de las cosas en vez de una descripción objetiva de los lugares visitados.

\section{Libro Impresiones y paisajes}

Los apuntes que Berrueta pedía a sus alumnos, en Lorca, con un impulso adicional del profesor que reconoció el talento del joven, se convirtieron en unos textos - relatos de viajes y ensayos - recogidos y publicados por el autor en volumen Impresiones y paisajes en 1918. Se trata del primer libro de un joven aspirante a escritor, que anteriormente ya había publicado unos pocos textos en las revistas.

A pesar de estar basado en las excursiones de Berrueta, el contenido de los textos y la estructura del libro no reflejan la cronología y el programa oficial de los viajes. Una parte de los textos está dedicada a Castilla y otra a Granada, mientras que las secciones tituladas "Jardines" y "Temas" no se refieren a espacios concretos. A diferencia del género de relatos de viajes, en Lorca no encontramos fechas ni lugares que motivaron la escritura de un texto determinado. En algunos textos Lorca precisa el lugar visitado mientras que en otros solo aparecen alusiones a las ciudades, sin mencionarlas directamente. Varios lugares visitados, como Madrid, Segovia, El Escorial, se quedaron sin huellas textuales de este autor. La historia del viaje no corresponde con el viaje real en todos los aspectos, demostrando la subjetividad y arbitrariedad del autor, así como la fragmentariedad del género en cuanto a los temas tratados.

La primera obra de Lorca no provocó mucha atención, en comparación con su poesía y obras dramáticas, y pronto cayó en olvido. Como explica García-Posada (1998: 9), todos leen esta obra de Lorca "bajo el peso de la sombra posterior", aunque la acogida de la obra en 1918 fue positiva. La crítica tradicional destacaba las erratas del libro temprano de Lorca, "las torpezas sintácticas, las ingenuidades expresivas, los tópicos conceptuales y el exceso de literatura ajena leída y sorbida con avidez" (García-Posada 1998: 10) o "incorrecciones, infinitas erratas y desequilibrios lingüísticos, vacilaciones ortográficas, ingenuos 
andalucismos, puntuación irregular e improvisada" (Chiappini 2000 145146). La crítica también citaba la actitud "reacia" (Lozano Miralles 2017: 14) de Lorca hacia la obra de su juventud. Últimamente, sin embargo, se ha reconocido su valor como la "búsqueda de una voz literaria propia" (Valdivia 2008: 63). De hecho, la mayoría de los estudios de esta obra es de fecha reciente, lo que en parte puede explicarse por el hecho de que la literatura de viajes ha empezado a valorarse positivamente en las últimas décadas. Asimismo, se ha hecho una revalorización de este libro, en el que se encuentran los primeros pasos literarios de Lorca en el periodo de su alejamiento de la música y el primer encuentro con los géneros literarios. Los estudios actuales demuestran que esta obra es de suma importancia para comprender la poética de Lorca, mostrando en ella las constantes que vertebrarían su obra posterior. Uno de los estudiosos de su obra, Pablo Valdivia (2008: 63), destaca que el mismo Lorca en 1935 declaró que toda su obra literaria estaba en ese libro.

Teniendo en cuenta la intención de Berrueta de realizar viajes de estudios y visitas a los monumentos culturales en amplio sentido de la palabra, en Impresiones y paisajes aparecen textos que comparten características con ensayo. Según la teórica de literatura de viajes, Idoia Arbillaga (2005: 38), el género de viajes a principios del siglo XX presenta acercamiento al ensayo. Los textos de Lorca, especialmente los incluidos en "Jardines" y "Temas", comprueban esta evolución del género, haciendo que muchos críticos consideraran sus textos principalmente como ensayos bajo influencia de su predecesor Unamuno.

Según Arbillaga (2005: 41), en el siglo XX los relatos de viajes ya no sirven para educar al lector sobre la cultura y la sociedad descritas, sino para transmitir las impresiones del viajero. Desde el siglo XIX el objetivo del viajero era captar la emoción, expresar los sentimientos provocados por el viaje, aunque sin excluir reflexiones críticas (Arbillaga 2005: 3637). El paisaje motiva una meditación metafísica (Arbillaga 2005: 36-37) y también es portador de un significado o un mensaje emocional, como una metáfora del humor del viajero que lo describe (Mainer 2004: 192).

\section{3. ¿Cómo eran y cómo percibía Lorca sus viajes?}

El joven Lorca no estaba muy interesado en reproducir fielmente la realidad percibida en los viajes. Es más, sus viajes eran unas "caminatas sentimentales" (García Lorca 2017: 63), en palabras del autor. Más que el paisaje le interesaba la impresión, la repercusión del paisaje en el alma. 
El mundo exterior será un reflejo de lo que siente. Así, desde este libro el joven escritor ya marca su camino literario y demuestra qué significa la literatura para él - la manera de expresar los estados anímicos, el mundo interior del escritor, es decir, es una forma de introspección. García-Posada (1998: 10) incluso opina que los textos nacieron de una necesidad, íntima e irreprimible, porque la literatura para Lorca fue una manera de comprender a sí mismo y expresar los problemas existenciales que le torturaron en ese periodo.

Su libro es declaradamente una visión, algo subjetivo, parcial, fragmentario. Lorca hacía diferencia entre el espacio visitado, como un objeto físico, y el paisaje como la imagen del mismo. Es más, en su obra aparecen los paisajes del alma y la función poética y la referencial se van alternando, siendo la función poética predominante. Se confirma una de las características de la literatura viajera contemporánea - la percepción de objetos observados es de mayor importancia que el objeto en sí mismo. La relación entre el observador y el objeto observado cobran mayor relevancia, según opina Julio Peñate Rivero (2005: 62-63), mientras que Miguel García-Posada (1998: 9), concluye, al respecto, que esta obra de Lorca demuestra que su autor "aún no sabe imponer su distanciamiento". Para Lorca, entonces, el relato de viajes llega a ser otro viaje, más intenso aún, por los recuerdos, marcados por la melancolía al comprender el encanto de las cosas (García Lorca 2017: 63).

El contexto en el que aparecen los textos incluidos en Impresiones y paisajes y la actitud del autor en ellos quedan más esclarecidos con la lectura de las cartas y los telegramas que Lorca escribió a sus padres durante los primeros viajes por España. Se trata de unos textos altamente explicativos, pero concisos, en cuya brevedad destacan los detalles elegidos por Lorca como los más relevantes en relación con el viaje. Y en esta elección de Lorca podemos observar su actitud ante los viajes y lugares visitados en un tono sincero, directo, por momentos hasta ingenuo. Mientras que en Impresiones y paisajes aparecen paisajes y la descripción impresionista del autor, en las cartas hallamos una expresión abierta e inmediata de los sentimientos y la actitud ante las cosas percibidas. Podríamos decir que las cartas complementan los relatos y ayudan a comprender la visión que de los lugares visitados tenía su autor.

En esas cartas predomina el entusiasmo del joven viajero, la alegría de estar viviendo y experimentando cosas nuevas y desconocidas. Así se confirma que el viaje es un acto de transgresión, dado el abandono de lo cotidiano y habitual para entrar en el reino del Otro (Wolfzettel 2005: 13), cuya experiencia ejerce fuerte influencia sobre el viajero e introduce 
cambios en su modo de sentir la vida. En Lorca podemos encontrar múltiples referencias a este aspecto de sus viajes, aunque él destaca principalmente los momentos pedagógicos y educativos: "En seguida que llegamos y nos colocamos me dijo Don Martín el plan de estudios que debía seguir y he comenzado mi tarea" (García Lorca 2017: 240). Luego: "Sigo por aquí enterándome de tantas cosas que no sabía y que hacen falta para una cultura un poco sólida" (García Lorca 2017: 241). Para concluir: "Desde luego os puedo decir que he aprendido muchas cosas y de mucha necesidad para una persona educada finamente" (García Lorca 2017: 246). Según se observa, el viaje de estudios ha cumplido su finalidad y Lorca confirma el aprendizaje de distintas materias en su curso, aunque también demuestra desarrollo personal durante el mismo.

En el "Prólogo" de Impresiones y paisajes Lorca declara que sus textos representan una interpretación, pero no solo de lo visto sino también de "recuerdos, de paisajes, de figuras" (García Lorca 2017: 57):

Todas las escenas que desfilan por estas páginas son una interpretación de recuerdos, de paisajes, de figuras. Quizá no asome la realidad su cabeza nevada, pero en los estados pasionales internos la fantasía derrama su fuego espiritual sobre la naturaleza exterior agrandando las cosas pequeñas, dignificando las fealdades como hace la luna llena al invadir los campos. Hay en nuestra alma algo que sobrepuja a todo lo existente (García Lorca 2017: 57).

La imaginación y los sentimientos tienen prioridad ante la realidad objetiva. La actitud principal del autor es la interpretación de lo visto y percibido, en una mezcla de ficción y realidad, es decir, la imagen final es la realidad pasada por el pincel de fantasía. Se trata de un aspecto muy presente en el género de literatura viajera, pero con frecuencia no pronunciado abiertamente, tal y como lo hizo Lorca. Los autores de los relatos de viajes no son solo viajeros, son intérpretes de la realidad cultural, lo que se observa claramente en la elección lorquiana de forma textual, en parte relatos de viajes, en parte ensayos.

La mirada del viajero nunca es una mirada inocente, ella nos descubre cómo se observa y reproduce lo visto por medio de la escritura. En ella influye el guía de viaje, pero aún más el bagaje literario y cultural del autor. López Plaza (2014: 137) considera que el libro de Lorca se halla entre la herencia de la estética del 98 (Antonio Machado, Las soledades) y el modernismo y simbolismo (de Juan Ramón Jiménez, Jardines lejanos). Lozano Miralles (2017: 38-39) presenta una opinión más precisa: 
Unamuno influyó en el concepto de ensayo a partir de la descripción de una experiencia determinada. De Azorín es la técnica descriptiva, mientras que de Machado heredó la actitud ante el paisaje y las gentes. En "Jardines" el mismo crítico reconoce la influencia modernista de Rubén Darío, mientras que en "Temas" hay paisajes emocionales, típicos del romanticismo. Según Luis García Montero (2016), Lorca se formó en una cultura romántica, con la crisis de un yo luchando contra el sistema injusto. Asimismo, en varios textos se nota la recepción lorquiana de la visión romántica de los viajeros del siglo XIX junto con la voluntad de dar una interpretación personal a la literatura tópicamente andalucista (Lozano Miralles 2017: 39). Sin embargo, a pesar de sus deudas con la tradición literaria española, la crítica ha reconocido que Lorca en Impresiones y paisajes estuvo buscando su propio camino literario.

\section{El pasado y el presente español vistos por Lorca}

Las imágenes ofrecidas por el viajero no solo representan una interpretación y construcción discursiva de la realidad observada, sino que permiten ver unas actitudes anteriores al viaje, imaginaciones previas y/o prejuicios sobre los lugares visitados. Lorca nos deja saber con qué influencia y con qué ideas partió de viaje, mostrando que la imagen, tal y como había explicado Claudio Guillén (1994: 118), siempre nace entre la escritura y la experiencia. Lorca, en uno de los momentos de reflexión, demuestra su postura ante tales cuestiones:

Antes de contemplar una maravilla ya teníamos de ella noticias y fantaseamos su forma soñándola, soñándola hasta hacerla un imposible..., por eso nos vemos defraudados casi siempre al contemplar un monumento del que habíamos oído hablar. Pasamos a través de los campos, a través de las ciudades sin habernos detenido casi nada y nuestros ojos siempre abiertos pretenden retratar todo, y sentirlo todo, pero nos viene el sueño y el cansancio y el hastío (García Lorca 2017: 169).

Esa imaginación previa no pocas veces dirige y condiciona la mirada del viajero, ejerce fuerte influencia sobre la visión de los lugares visitados y decide el tono de los relatos de viajes. Así, Lorca dirá que la realidad percibida no corresponde con la poesía de Verlaine (García Lorca 2017: 112) y, a veces, la realidad comparada no solo con la poesía sino con la literatura en general, decepciona frente a las ensoñaciones previas idealizadas: "hasta hacerla un imposible", dice Lorca. La poesía estaba desaparecida de la realidad experimentada por el joven poeta. 
Esta postura de Lorca puede relacionarse con otro aspecto presente en sus primeros textos - la relación conflictiva entre el pasado y el presente. Los viajeros extranjeros a finales del siglo XIX y a principios del siglo XX buscaban en España manifestaciones de progreso y modernidad, haciendo que en la literatura española se abriera un debate sobre la relación entre el pasado anclado en tradiciones y el presente con señales de modernidad. Lorca se convierte en uno de los testigos de los nuevos tiempos y de los cambios que acompañaron la modernización. En su obra hay distintas reflexiones sobre la desaparición del pasado y sus huellas en el presente: "Pronto desaparecerá el jardín. Hay que borrar las obras de los otros siglos... Es triste" (García Lorca 2017: 163). El poeta se identifica con la melancolía de los jardines y la impresión predominante del autor es la melancolía por los cambios provocados por la mano humana que anula la vida y obra de otros tiempos en la actualidad, así que exclama: “Esta monomanía caciquil de derribar las cosas viejas...!”. En la descripción de Baeza, Lorca escribe que urbanizar una plaza para él significa una "tremenda palabrota" que derriba "el encanto viejo". Así, Baeza se erige como una ciudad sumida en un abandono, concluyendo que se trata de una ciudad solitaria de "calles tristes y silenciosas" y "ruinas color sangre" (García Lorca 2017: 129-134). García Montero en este texto reconoce el paradigma del simbolismo, con el rechazo de la ciudad marcada por progreso tecnológico e industrial y una defensa de "la ciudad que es un pozo de historia" (García Montero 2016).

Lo antiguo, los restos del pasado conservados en el presente, es lo que obtiene valoración positiva de Lorca: "Burgos es maravilloso, tanto en lo antiguo (que es de lo mejor de España) como en lo moderno" (García Lorca 2017: 237). Con los tiempos modernos, observa Lorca, desaparece no solo el pasado sino también lo poético, lo que buscaban todos los viajeros en España y, al parecer, no solo los viajeros extranjeros sino los españoles al igual: "Se murió el madrigal cuando nació ferrocarril" (García Lorca 2017: 164). Hay que añadir, en este aspecto, que Lorca pensaba poner título Caminatas románticas por la España vieja a la colección de sus textos. Este título también nos explica cómo fue la ruta que Berrueta eligió para sus excursiones con objetivos pedagógicos, con una tendencia a visitar los monumentos del pasado. Asimismo, el título nos ayuda a comprender la actitud de Lorca al respecto de los viajes - Lorca buscaba y hallaba algo romántico en estos viajes.

El pasado, como el tema recurrente en los relatos de viajes, siendo las ciudades antiguas unos lugares obligatorios en los viajes por España, inspira distintas actitudes y emociones en los viajeros. Junto con lo poético, 
para Lorca la percepción del pasado en las ciudades como Ávila o Zamora inspira emociones fuertes del olvido del presente y la imposibilidad de mirar hacia el futuro: "(...) se olvidan de lo que son para mirar hacia lo que no vendrá, y si a su vez piensan en el porvenir llorarán de un triste y amargo desencanto..." (García Lorca 2017: 61). La dejadez y la falta de desarrollo, a pesar de la valoración positiva de los espacios antiguos, no pueden competir con la necesidad de aceptar el futuro. Ciudades antiguas inspiran cansancio con su quietud y ausencia de movimiento dinámico de la vida. La vida no se abre al futuro por el peso de su pasado, opina Lorca. Sin embargo, surge en el autor un aire de optimismo o tal vez de protesta cuando dice que la juventud "llegó y seguirá llegando" y hasta un "aeroplano triunfador" como señal de progreso. En este contexto, la modernización anteriormente rechazada se une con el valor indiscutible, la juventud española. En el periodo de las vanguardias, cuando nacen los textos de Impresiones y paisajes, lo joven en el contexto de renovación de una España estática se promueve como la salvación.

La actitud de Lorca, a pesar de las reflexiones aparentemente contradictorias, no es ambivalente. Lorca valora la tradición y defiende la salvación de los monumentos culturales e históricos, reconociendo el aire poético del pasado frente a los elementos modernos que intentan destruir o derrumbar la identidad pasada. Por otra parte, eso no significa que Lorca quiere vivir en el pasado. Como los vanguardistas, el joven viajero mira hacia el futuro y destaca el valor de la juventud. Los aspectos poéticos de un lugar no excluyen su orientación hacia el futuro, es decir, Lorca aboga por la coexistencia de la tradición y los tiempos nuevos. Las actitudes casi noventayochistas sobre la tradición y la modernización de España desembocan en una valoración de lo poético y pasado, presente en los tiempos modernos junto con el progreso. Asimismo, el joven observador de la España moderna lamenta que "Se están perdiendo los jardines españoles" (García Lorca 2017: 161), sustituidos por el parque inglés, pronunciándose a favor de lo local y nacional frente a las modas extranjerizantes.

Aunque los relatos de viajes expresan algunas preocupaciones relacionadas con el periodo y espacio de viaje, este género literario no se caracteriza tanto por las cuestiones políticas y sociales actuales y es importante si estas cuestiones llegan a dominar sobre otros aspectos en relación con el viaje (Albuquerque 2006: 81-82). Por lo tanto, la crítica social, relacionada con el tema de dejadez y falta de vida en unos lugares antiguos y abandonados, aunque no muy frecuente en la obra lorquiana analizada, por momentos obtiene gran relevancia: 
Quizá algún día, teniendo lástima de los niños hambrientos y de las graves injusticias sociales, se derrumbe con fuerza sobre alguna comisión de beneficencia municipal donde abundan tanto los bandidos de levita y aplastándolos haga una hermosa tortilla de las que tanta falta hacen en España... Es horrible un hospicio con aires de deshabitado, y con esta infancia raquítica y dolorosa. Pone en el corazón un deseo inmenso de llorar y un ansia formidable de igualdad... (García Lorca 2017: 190).

Todas las descripciones apuntan que la actitud predominante de Lorca es el impresionismo, una melancolía jovial ante el mundo imperfecto.

\section{Imagen de España e imagen de sí mismo}

En los relatos de viajes pueden identificarse elementos que, según su autor, son importantes para construir la imagen de una identidad (Nucera 2002: 245-246). Entonces, ¿cómo es la España de Lorca?

Las escenas cotidianas, tan frecuentes en la literatura viajera, no ocupan mucho espacio en los textos de Lorca. El costumbrismo, el color local de los pueblos y los hábitos de la gente en Lorca tienen menos importancia que el paisaje percibido y el paisaje del alma que lo percibe. Según Luis García Montero (1990: 21), Lorca rechaza el costumbrismo y la exaltación de lo local, así que su obra no cabe dentro de un regionalismo tópico, a pesar de describir lugares y regiones paradigmáticos españoles.

Uno de los pocos ejemplos costumbristas lo encontramos en un texto de título muy revelador: "Tarde dominguera en un pueblo grande". En este texto se nota una tendencia hacia la generalización, típica de relatos de viajes - no es una tarde de domingo sino una tarde dominguera, apuntando así a la repetición de las mismas circunstancias en un pueblo. El autor no precisa del pueblo ni de la fecha - es un pueblo cuyas escenas se convierten en el emblema de lo rural y su vida cotidiana: los niños en trajes nuevos que se estrenan los domingos y con miedo a estropearlos o ensuciarlos. Las muchachas que pasean, ríen, cantan, una pareja que se besa, una orquesta de música.

En el texto dedicado a Baeza, la "Ciudad perdida", según Lorca, también se reconocen las influencias simbolistas de Antonio Machado, al que el poeta conoció en sus viajes con Berrueta, principalmente en el motivo del coro de niños, una huella de la tradición que se iba perdiendo, pero que, por otra parte, tenía influencia en el simbolismo español (García Montero 2016).

Aunque Lorca no dedica muchos apuntes a las escenas cotidianas de su viaje, por momentos podemos observar su interés por 
lo intrahistórico, especialmente si conlleva elementos dramáticos y existenciales. Así, en Burgos, el joven viajero observa cuidadosamente la vida dentro de un claustro y reflexiona sobre los motivos que inspiraron a las monjas entrar en clausura. Deseando descubrir el sentido de la vida monástica, Lorca deja libre su imaginación y opta por destacar su posible protesta contra la sociedad, conflictos emocionales, temas de amor y pecado. En fin, lo que se presenta en el texto es la vida concebida como un drama existencial, llena de tensión. Esta convicción, sugiere Ian Gibson (1985: 168), ha quedado confirmada por las visitas a otros monasterios. En varios personajes destacados en esta prosa temprana, Lorca percibe el rechazo de la vida mundana y el monasterio como posible espacio de paz y serenidad. Sin embargo, en la Cartuja de Miraflores, Lorca también observa señales de futilidad e hipocresía de la vida monástica, viendo que muchos monjes no han dejado del todo las costumbres de la vida mundana y observando en ellos intentos de represión sexual. El espacio monástico es identificado entonces en términos de auto-castración, renuncia, negación de la humanidad esencial de hombre, según Gibson (1985: 171), un "teatro de tormentos", con su inquietante silencio. García Posada (1998: 25) en esas descripciones encuentra el vitalismo dionisiaco de Lorca, lo que confirma la actitud de Lorca hablando de amor: "El alma siente deseo de amar, de amar locamente y deseo de otra alma que se funda con la nuestra" (García Lorca 2017: 84). La frustración erótica, aludida en estos primeros escritos, será un tema recurrente e importante en la obra posterior de Lorca.

Javier San José Lera (2012: 239) opina que en la descripción del paisaje el que guía al joven Lorca es "el oído musical". Este autor propone estudiar la relación entre la música y la literatura en la obra de García Lorca diciendo que "la primera estética lorquiana se forja en contacto con - y no por abandono de la música" (San José Lera 2012: 234). Según el mismo autor, la música europea, especialmente la obra de Debussy, muy popular en las vanguardias españolas, modela los planteamientos estéticos de Lorca y alimenta sus obras literarias.

La imagen de España, podemos decir, se esconde detrás de las impresiones auditivas y visuales, dado que el paisaje lorquiano está formado por colores y sonidos. El soporte musical se reconoce desde el principio por los títulos de los textos, que funcionan como unas macroestructuras musicales. Al nivel léxico, también aparecen múltiples referencias a la música: modular, sonido, melodía, cantar, musical, acorde, sonar... Los sonidos entran a formar parte de las sinestesias, metáforas, comparaciones y descripciones en general. Al nivel lingüístico, según San 
José Lera (2012: 239), hasta los puntos suspensivos pueden relacionarse con la música, dado que tienen distinta longitud en los textos de Lorca. Se trata, según opina el mismo crítico, de la musicalización generalizada del texto. Marisa Martínez Pérsico (2008: 39-42), sin embargo, considera que la musicalidad de la obra trasciende estos fenómenos "de superficie": "Las Impresiones lorquianas nos ofrecen la comunión holista entre sonido y paisaje”.

Los elementos musicales empleados para describir el espacio permiten identificar diferencias entre distintos lugares y regiones españoles. Así, la imagen de Granada se construye a través de los sonidos de la naturaleza (el río), de sonidos populares (canciones), sonidos de las campanas, sonidos de agua (lluvia, fuentes), etc. (San José Lera 2012: 239240). Granada es una ciudad llena de contrastes, marcada por contrapunto y música polifónica, concluye Martínez Pérsico (2008: 40), mientras que Castilla es caracterizada por un silencio monocorde y ese silencio es, según la misma autora, la materialización auditiva de la muerte, dado que una pieza musical termina y se resuelve en el silencio final (Martínez Pérsico 2008: 32). Así, la autora confirma su hipótesis de que en la obra lorquiana existe un isomorfismo entre escenarios o paisajes naturales y sistemas de representación musical (Martínez Pérsico 2008: 31).

El léxico que acompaña y marca el paisaje castellano abarca vocabulario ya relacionado con esta región en la obra de la Generación del 98: inquietud, muerte, melancolía, misticismo, callado, plomo, etc. Como resultado se da una visión de Castilla decadente, llena de melancolía plomiza. La palabra más frecuente en la obra, según apunta Chiappini (2000: 150), es la "quietud", pero precisamente esta sensación es la que Lorca no consigue alcanzar, sintiendo a su vez una "amarga tranquilidad", "paz pasional" o "lúgubre armonía". En vez de la quietud deseada, el libro demuestra una tensión interna y la escisión del alma de Lorca como impresiones dominantes en la obra. Gaetano Chiappini (2000: 157) en ello observa las señales de la crisis moral, religiosa y existencial, vivida por Lorca en aquellos años. La percepción de Lorca depende de una mirada enfocada hacia la busca de la esencia espiritual de los seres y las cosas, dice Eugenia Sanz (2004: 27), mientras que el viaje llega a ser un consuelo espiritual de los problemas sentimentales.

\section{Conclusiones}

El tema principal de la primera obra publicada de Lorca son los paisajes, tanto rurales como urbanos, tanto exteriores como su 
reflejo en el alma del joven, tal y como lo sugiere el título. La mirada del viajero debe ser verosímil y reflejar el mundo objetivo, sin embargo, la mirada de Lorca como joven viajero transforma el mundo contemplado y se convierte en diferentes reflexiones y divagaciones, llevada por las impresiones. Según nos explica Maurer (1986: 13), el libro Impresiones y paisajes pudo ser descriptivo y costumbrista, pero el joven Lorca concibió la literatura como el medio para expresar sus estados anímicos y como "ejercicio de introspección". El mismo crítico también llega a considerar la posibilidad de que para Lorca "el mundo exterior será un reflejo de lo que siente" (Maurer 1986: 13). Poner alma en todo lo que observa, según Ian Gibson (1985: 196), es una idea que Lorca había recogido de su profesor Berrueta. El libro es una interpretación del mundo mediante el alma, tal y como escribe en el "Prólogo": "Hay que interpretar siempre escanciando nuestra alma sobre las cosas, viendo un algo espiritual donde no existe, dando a las formas el encanto de nuestros sentimientos" (García Lorca 2017: 58). Es una contemplación de paisajes cuyo fruto no es una descripción realista. Lo que importa más son las impresiones o, como lo dice Sainz (29) "la expresión del sentimiento vinculado a la contemplación del paisaje”.

La mirada del autor transforma lo visto, lo poetiza, musicaliza y añade una reflexión sobre los hechos artísticos. La autoimagen de España construida por Lorca entonces se convierte en una visión íntima, romántica y lírica, la que permite ver cómo su autor percibe el mundo en su alrededor y cómo percibe a sí mismo en un viaje de autoconocimiento.

\section{BIBLIOGRAFÍA}

Albuquerque-García, Luis. "El 'relato de viajes': hitos y formas en la evolución del género". Revista de literatura, Núm. 145 (2011): 15-34. Web. 18 Jul. 2018.

Arbillaga, Idoia. Estética y teoría del libro de viaje: el "viaje a Italia" en España. Málaga: Analecta Malacitana, 2005. Impreso.

Chiappini, Gaetano. "Algunas hipótesis de lectura de Impresiones y paisajes: la difícil composición de la totalidad-quietud". Theodor Berchem \& Hugo Laitenberger (Coords.). Federico García Lorca: Actas del coloquio internacional, Sevilla: Fundación El monte, 2000: 145-157. Impreso.

García Lorca, Federico. Impresiones y paisajes. Madrid: Cátedra, 2017. Impreso. 
García Posada, Miguel. "Prólogo: Los escritos juveniles de Federico García Lorca". Federico García Lorca, Obras completas IV, Primeros escritos, Madrid: Galaxia Gutenberg, 1998: 9-32. Impreso.

García Montero, Luis. "La poesía es un territorio que permite ofrecer un dolor ordenado", Conferencia de Luis García Montero sobre el magisterio de Antonio Machado en la poética del joven Lorca. Transcripción y notas de Marisa Martínez Pérsico, 2016. Web. 17 Oct. 2019. https://circulodepoesia.com/2017/01/la-poesia-esun-territorio-que-permite-ofrecer-un-dolor-ordenado-machadoen-lorca-conferencia-de-luis-garcia montero/

Gibson, Ian. Federico García Lorca: De Fuente Vaqueros a Nueva York (1898-1929). Barcelona / Buenos Aires / México: Ediciones Grijalbo, 1985. Impreso.

Guillén, Claudio. "Imágenes nacionales y literatura". Anales de literatura española, Núm. 10 (1994): 117-145. Web. 12 Jun. 2012.

López Plaza, Angélica. "Ruina: imagen poética en Federico García Lorca". Revista de Estudios Hispánicos, Núm. 1 (2014): 135-156. Web. 16 Jul. 2018.

Lozano Miralles, Rafael. “Introducción”. Federico García Lorca. Impresiones y paisajes, Madrid: Cátedra, 2017: 13-52. Impreso.

Mainer, José-Carlos. "Galdós, de viaje por Castilla”. Julio Peñate Rivero (Ed.). Relato de viajes y literaturas hispánicas, Madrid: Visor libros, 2004: 185-204. Impreso.

Martínez Pérsico, Marisa. "Pentagrama de paisajes". Extravío, Revista electrónica de literatura comparada, Núm. 3 (2008): 27-44. Web. 24 Jul. 2018.

Maurer, Cristopher. "Sobre la prosa temprana de García Lorca (19161918)". Cuadernos Hispanoamericanos. Homenaje a García Lorca, Núm. 433-434 (1986): 13-30. Web. 07 Sep. 2018.

Nucera, Domenico. "Los viajes y la literatura". Armando Gnisci (Ed.). Introducción a la literatura comparada, Barcelona: Crítica, 2002: 241-289. Impreso.

Peñate Rivero, Julio. "Javier Reverte: el viaje, la literatura y el libro". Julio Peñate Rivero (Ed.). Leer el viaje, Madrid: Visor libros, 2005: 4564. Impreso.

Peragón López, Clara Eugenia. “El alma que allí canta... Es el alma de su Andalucía. La presencia de Andalucía en la obra de Federico García Lorca". Tonos Digital. Revista electrónica de estudios filológicos, Núm. 22 (2012): S. P. Web. 07 Sep. 2018. 
San José Lera, Javier. "Federico García Lorca: literatura y música europea en tres movimientos”. Studi Ispanici, Núm. 37 (2012): 233-251. Web. 07 Sep. 2018.

Sainz, Eugenia. "Impresiones y paisajes de Federico García Lorca: modernismo y mirada interartística". Confluencia. Revista hispánica de cultura y literatura, Núm. 1 (2004): 27-44. Web. 17 Jul. 2018.

Valdivia, Pablo. "El viaje iniciático de Federico García Lorca". Andalucía en la historia, Núm. 23 (2009): 60-63. Web. 12 Sep. 2018.

Wolfzettel, Friedrich. "Relato de viaje y estructura mítica". Leonardo Romero Tobar \& Patricia Almarcegui Elduayen (Eds.). Los libros de viaje: realidad vivida y género literario, Madrid: Akal / Universidad Internacional de Andalucía, 2005: 10-24. Impreso.

\section{VOYAGES AND DISCOVERIES OF FEDERICO GARCÍA LORCA}

\section{Summary}

We propose to question the meaning of travel in the book Impressions and landscapes by Federico García Lorca and related to this, the concept of exterior and interior discovery, provided in this case by the actual trip.

We started with the idea that the voyage was a practice promoted by the Krausists and accepted by the Generation of 98 as an instrument to get to know Spain closely, a vital Spain below stereotyped visions. From there we will question how García Lorca's voyage with other students, organized by his teacher Berrueta as a collective pedagogical field trip, based on visits to museums and cultural monuments, ends in an inner journey as his last expression.

The subject of this work will also be the imaginary interpretation of the vision of Spain in decline, which has caused García Lorca's concerns about the future of Spain.

Finally, the way in which the self-image of Spain constructed by Federico García Lorca becomes an intimate, romantic and lyrical vision will be questioned. The boundaries between fiction and reality turn out to be blurred and the trip through different Spanish cities for the author of Impressions and landscapes obtains an initiatory structure.

Keywords: Federico García Lorca, Impressions and landscapes, voyages, visions, reality. 